\title{
Transformation of the Educational Ecosystem in the Singularity Environment
}

\author{
Kateryna Andriushchenko \\ Kyiv National Economic University, Kyiv, Ukraine \\ https://orcid.org/0000-0002-6274-5310 \\ Vita Kovtun \\ Kyiv National Economic University, Kyiv, Ukraine \\ https://orcid.org/0000-0001-7212-6700 \\ Oleksandra Cherniaieva \\ Interregional Academy of Personnel Management, Kyiv, Ukraine \\ https://orcid.org/0000-0002-6981-2491 \\ Nadiia Datsii \\ Zhytomyr National Agroecological University, Zhytomyr, Ukraine \\ https://orcid.org/0000-0003-0640-6426 \\ Olena Aleinikova \\ University of Educational Management, Kyiv, Ukraine \\ https://orcid.org/0000-0002-4876-3563 \\ Anatolii Mykolaiets \\ Interregional Academy of Personnel Management, Kyiv, Ukraine \\ https://orcid.org/0000-0003-2580-0736
}

\begin{abstract}
This study was aimed at creating an effective model of the educational ecosystem in a singularity environment. The study is based on a system of general scientific methods of scientific knowledge, in particular, the method of expert assessment, the method of analogy and comparative analysis. The experts, with the support of facilitators, visualized the possible future of education as a symbiosis of individual and collective learning paths that connect learners with many learning spaces and educational opportunities. To ensure the operability of such a model of the educational ecosystem, it is necessary to create tools and processes that support personal and collective learning and development throughout life, including: processes and tools that help determine the goals of learners; educational processes integrated into the educational trajectory and developing various aspects of personal and collective existence through holistic educational experiences, including play and co-creation; processes and tools that measure
\end{abstract}


learning outcomes; educational spaces and technologies that help to combine personal and collective educational trajectories, coordinating individual educational needs with the evolving needs of communities. These processes can be integrated into "ecosystem" systems of educational process management (in which personal and collective learning paths can be combined, and which connect learners with many learning spaces and educational opportunities).

Keywords: Singularity; Educational ecosystem; Competencies; Selfguided education

\section{Introduction}

The rapid development of material and digital technologies and new management tools in the 21st century gives mankind unprecedented opportunities to create a desired future on a global scale. At the beginning of the 20th century a new hypothesis related to technological evolution (Armstrong, 2017) appeared, namely the concept of technological singularity (TC), which is closely connected, first of all, with the rapid development and introduction of innovations. In 1996, when the three main factors of the economy (labor force, nature, capital) were related to information (information and communication technologies of ICT), a new theory - the digital economy arose (Tapscott, 1997).

According to scientists, in 2045 artificial intelligence will exceed human intelligence (Mead \& Kurzweil, 2006). Some scientists call technical evolution a singularity. With all the positive aspects, it is necessary to take into account that technical evolution also brings big threats and changes for the education system. At the recent Global Education Forum in Dubai, Harry Patrinos (World Bank Education Manager), said about how workplace automation will affect the quality of learning and the skills that learners need to be competitive with regard to the speed of technical singularity (Psacharopoulos \& Patrinos, 2018). While industry is entering the fourth industrial revolution, education has stalled in its development, and what we attribute to transformations is not enough. In addition, it is necessary to recognize the fact that a large part of the education system is not ready for technical singularity. The industry is rapidly developing, the pace of technical singularity is surprising, while the education system is slowly lagging behind. Approximately $80 \%$ of the time teachers spend on administration and transfer of knowledge and only about $20 \%$ on emotional development (UNESCO, 2020). Technological singularity, which leads to the use of artificial intelligence in the educational process, contributes in the future to more effectively assess learners and focus on building relationships and the formation of emotional development in learners.

Masayoshi Son (he is the richest Japanese tycoon and the largest sponsor of technological singularity) predicts that in 30 years the number of smart robots on earth will be 10 billion and exceed the number of people (Kovtun et al., 2020). He argues that any industry created by humanity will be redefined: the medical industry, the automotive industry, the information industry, in general all the industries that have ever been created by humanity, even agriculture. Because 
the tools that we created in the past were inferior to the human brain. Now tools are becoming smarter than themselves.

Education systems, built on the patterns of the century before last, are no longer meeting the requirements of the times. Given the development of exponential technologies in the information sphere, the production of new materials, biology and genetics, the future "comes" to us faster than we manage to react to what is happening. Adaptive and conservative models of education are not just ineffective - they pose a tremendous danger to our future, making us unprepared and blind to the coming changes. First of all, education needs to stop reproducing outdated models of thinking and activity. The time has come to carry out the required transformations, and we need a qualitatively new educational paradigm that meets the challenges of the complex world of the 21st century (Global Education Futures, 2020).

According to UNESCO (UNESCO. 2020), there are 750 million illiterate people on the planet who live mainly in developing countries in Africa, Asia and Latin America - and one of the main goals of the UN sustainable development is the complete elimination of illiteracy by 2030. The global demand for higher education continues to grow: by 2025. the number of learners in the world should increase by 95 million, and in order to satisfy this demand, it is required to open three new universities every week over the next 10 years (Jacobs, 2014).

According to the Hays Global Skills Index (Hays Global Skills Index, 2018), the growing mismatch of employee competencies with employers' requirements remains one of the key market problems labor for all major economies of the world. That is - even without major changes, education can remain one of the most sought-after areas of society. From this point of view, the main tasks of education in the coming decades will be to increase the capacity of educational institutions, develop curricula that are more consistent with the requirements of the labor market, as well as reduce the cost of learning with the help of new educational technologies.

The transformation of the education sector in accordance with modern challenges is inevitable, and the technologies that have already become the driver of large-scale socio-economic changes have great potential for use in schools. Already today, the use of big data processing technologies, artificial intelligence, personalization in learning is no longer the subject of academic discussion and is becoming the content of real projects, educational services and platforms. To be able to respond to global challenges, participants in the educational ecosystem must very well understand the main trends in its development. This is especially important for our country, for historical reasons it has for many decades been exposed to "raw material dependence" and the accompanying significant centralization of public administration in everything, including education. Today, when natural wealth ceases to be the basis and guarantee of success of individual countries in global competition, it is necessary to focus all our attention on the development of the only truly inexhaustible resource for creating a better future for everyone and everyone - human potential - in all its manifestations. 
The aim of this paper is to form an effective model of the educational ecosystem in a singularity environment as a symbiosis of individual and collective learning paths that connect students with many learning spaces and educational opportunities.

\section{Literature review and problem statement}

Currently, a paradigm shift in the development of mankind is taking place. A fundamental transformation of all forms of life activity is underway throughout the world. Today's world needs innovations, since the resource base of nature has been largely exhausted and only the innovative potential of man can lead the world forward. At the same time, the modern innovation process can be both manageable and spontaneous and unfocused. It is a clear understanding of the content and structure of modern innovative technological transformations such as information technology, artificial intelligence, biotechnology, nanotechnology, communications, etc. allowed Ray Kurzweil to formulate the law of acceleration of returns in 1999 (Kurzweil, 1999).

The research steps undertaken in this area by Eden, A. in 2012 in his essay "Singularity Hypotheses" indicate, on the one hand, insufficient theoretical elaboration of the problem, and on the other, the lack of effective mechanisms for implementing the planned social transformations (Eden et al., 2012). Researchers drew attention to the fact that, since technological progress, determines how we live, is constantly accelerating, there must come a moment when people can't keep up with technology - that is, it will come what mathematicians call a singularity (Neumann, 1993). But this time it will not be a feature in a certain physical system, but a feature in the history of mankind. Ulam S. systematized the idea of a singularity, which was considered as the evolution of cybernetic systems (that is, control systems), both biological (mainly the nervous system as a natural cybernetic system) and cultural (Ulam, 1958). The evolution of these systems consists of a sequence of metasystem transitions, each of which consists in the emergence of a next-level control system that selects between different states or instances of already existing lower-level control systems.

The ultimate limit of physical and social conditions is the point of singularity. In a mathematical sense, a singularity is a phenomenon in which the number of crises becomes infinite, and the gaps between them tend to zero (Vinge, 2008). Singularity is the point at which our old models will have to be discarded, where a new reality will reign. This is a world whose outlines will become clearer, approaching modern humanity, until this new reality obscures surrounding reality, becoming commonplace (Vinge, 2008). The scientist stated that society simply went to the limit of both physical reality, studied by natural and mathematical disciplines, and the social limit, studied by philosophy and social sciences (Vinge, 2008). The appearance in the social and philosophical sciences of the physical and mathematical concept of "singularity" is not accidental. According to American researchers, the singularity point will come in 2020 (Tsirel,2020) or in 2027 (Panov, 2020). 
The concept of the singularity was widely popularized by Raymond Kurzweil, who argues that the moment at which the mind of machines exceeds the human - let's call it the Turing point - is not only inevitable, but also awaits us over the next several decades (Kurzweil, 2008) In support of this idea, Kurzweil talks about the merging of people and machines, after which there will be many niches in which equivalent human autonomy will be claimed: embedded systems in self-governing devices, autonomous robots of lower functionality in larger intelligent creatures (Kurzweil, 2008). Later, Kurzweil developed the idea that technological singularity is a futuristic concept, where the intellectual capital of people in a constant "connect" with artificial intelligence is integrated into artificial intelligence (superhuman intelligence). In other words, people will become elements of information technology systems, and their manifestations will be limited by their functionality in these systems (Kurzweil, 2016).

Scientists in their study presented the idea of considering technological singularity as a predicted convergence of people and machines (Solez et al., 2013). Researchers are talking about combining the strengths of a person and a computer, where a person uses intuition, associations, and his understanding of processes, and the computer's function is to carry out cumbersome accurate calculations and expand the volume of operational and long-term human memory. The main message in the paper is the interaction of man and computer when the core value is formed (Solez et al., 2013).

In a study (Good, 1990) Irving John Good in the context of technological singularity defined the superintelligent machine as a machine that can significantly surpass all the intellectual actions of any person, no matter how smart he is. Since the ability to develop such a machine is also one of these intellectual activities, the superintelligent machine can build even more advanced machines. This will undoubtedly be followed by an "intellectual explosion", and the human mind will lag far behind the artificial. Thus, the first superintelligent machine will be the last invention that will fall on a person's lot, provided that the machine is humble enough and tells us how to keep it under control. And the likelihood that in the twentieth century the superintelligent machine will be built and become the last invention that a person will make is higher than the likelihood that this will not happen (Good, 1990).

In the idea of a technological singularity, human intelligence is replaced in many areas of activity. People gradually and steadily refuse to participate in the production process (Mole, 2011). In a study (Calum, 2018), the author suggests identifying several types of singularity: - technological, associated with the creation of artificial intelligence superior to human intelligence; - economic, in which acts of production and consumption reach absolute agreement and are combined; - political, when political governance as such becomes meaningless; cultural, the main feature of which is the transition from the total priority of successive artistic styles to the parallel, simultaneous existence of all the possible diversity of cultural forms, to the freedom of individual creativity and individual consumption of the products of this creativity. From the point of view of technological development, a researcher (Calum, 2018) connects technological progress with the economic crisis; avalanche-like innovation generates crisis 
phenomena in the social, cultural and economic life of people and is a mechanism for overcoming crisis situations. according to cyclical theories, destruction and creation in the development of matter are repeated forever.

Approximately 50 years ago, the American sociologist Alvin Toffler wrote in the book "Shock of the Future" that the continuous and accelerating process of change is the main trend of industrial civilization (Toffler, 1970). The impact of technological acceleration is especially pronounced in the mutually reinforcing spheres of "exponential" technologies: digital, biotechnological, and nanotechnological (Kurzweil, 2005).

Likewise, changes in social norms have also been under the influence of an accelerating trend over the past hundred years, albeit to a lesser extent. Accelerating change (Heylighen, 2015) is an integral qualitative characteristic of an industrial society, which was the result of three key events (Johannessen \& Sætersdal, 2020):

- the emergence of "social machines" for knowledge creation and innovation (from research universities and corporate research and development departments to regional and national innovation systems), which provide a steady flow of new technologies (Coser \& Mumford, 1972);

- the emergence of network technologies (from telegraph and television to the Internet and social networks), which are becoming a vehicle for the rapid spread of new technologies and norms (Bilan et al., 2017; Nitsenko et al., 2019; Andriushchenko et al., 2020).

- the emergence of institutions supporting the processes of globalization, which are gradually developing from agreements on free trade to systems of global technology standards, professional requirements and educational processes.

The concept of "ecosystem" began to figure in discussions about the future of education in the early 2000s, but there is still no single definition of it. Some define the ecosystem through a balance of different stakeholders (stakeholders) in the education process, including teachers and learners (Pearce \& McCoy, 2007; Hannon, 2017); others emphasize the role of the ecosystem as an alternative to the traditional education system (Knowledge Works, 2012). Increasingly, the concept of an ecosystem is used to refer to the collection of educational technology solutions (eg social media and educational platforms) that are available to individual learners and educational institutions.

In this study, the educational ecosystem can be defined as a dynamically evolving and interconnected network of educational spaces made up of individual and institutional providers of education who offer a variety of educational resources and experiences to individual and collective learners throughout their life cycle.

Studies in evolutionary biology, from where the concept of "ecosystem" is taken, offer a more precise definition: an ecosystem is a community of living organisms in connection with a natural inanimate environment (air, water, soil, etc.): for example. forest, coral reef, or lake (Chapin et al., 2002). Given this definition, we 
can point out some features of the educational ecosystem that may be inherent in them by analogy with biological ecosystems, in particular:

- diversity: different providers of education that play many different roles and ensure the structural stability of the ecosystem;

- maximum productivity and closed circulation of resources in the ecosystem:

- education providers enter into mutually beneficial relationships in which they create and reallocate resources among themselves, including interested learners, knowledge, quality assurance and funding (as opposed to earlier "hierarchical" educational organizations that tried to control the educational trajectory and future fate of learners, increasing competition within the system);

- the ecosystem creates the "maximum benefit" for society (for example, a developed ecosystem should provide skills learning on a scale comparable to secondary vocational education, with greater quality and lower costs);

- quick adaptability: ecosystems are able to adapt and respond to learner requests and changes in the institutional environment (this is a critical hallmark of ecosystems in relation to the earlier and more rigorous approaches of centralized educational systems);

- scalability: ecosystems can operate at different scales, from groups of learners or individual schools to the scale of the entire planet.

Accordingly, a fully developed educational ecosystem is an open and growing community of different education providers that serve the different needs of learners in a specific context or territory. A territory or region becomes the minimum unit of the educational ecosystem - while a separate educational institution (school, university, etc.) can never be a full-fledged ecosystem on their own, although they can have "ecosystem" properties and can become a central structural element of the ecosystem (like a large tree, in the crown of which a wide variety of organisms can live, from moss to birds). A full-fledged ecosystem requires not only providers of educational experiences, but also various integrators ("connectors") that create trajectories for learners through the system, help to record and record their achievements, find and connect public resources, etc. In this way, the educational ecosystem is always localized, it meets local needs and brings learners together in this context.

\section{Research}

The modern world is facing a huge number of threats, including climate change, declining biodiversity, growing risks of personal and collective security on a global scale, threats to global wealth and growing global inequality. All these threats are direct consequences of the dominant organization model of industrial civilization (Hansson, 1990) - and their mutual influence reinforces each other, creates the cumulative effect of growing global turbulence, and calls into question the ability of mankind to survive the next century. Amid these growing threats, management systems (including not only formal structures, but also cultural patterns and a dominant way of thinking) simply stop coping with the growing complexity. The reason for this is the mass education of the industrial 
era: it does not prepare for life in a complex world, does not develop thinking, reduces creative potential and innate ability to cooperate, deprives people of sensitivity and compassion.

Today, education is mainly aimed at maintaining the status quo and reproducing the values inherent in industrial society. Although in recent decades developed countries have been trying to change the current situation through the formation of a "knowledge economy", the seeming changes in fact largely continue the previous model and preserve all the old contradictions, including the imbalance between humanity and nature.

Any deliberate change in education systems in the 21st century should be inextricably linked with the solution of problems of economic, environmental and political injustice, and should create the possibility of free access and dissemination of human wisdom and welfare. It is necessary to develop a new model of society based on collective wisdom or "the fundamental pragmatism of life" (Baltes \& Staudinger, 2000), which plays a key role in decision making and human development. Figure 1 shows the process of transformation of society, which includes three stages: industrial society; knowledge economy; a society based on wisdom.

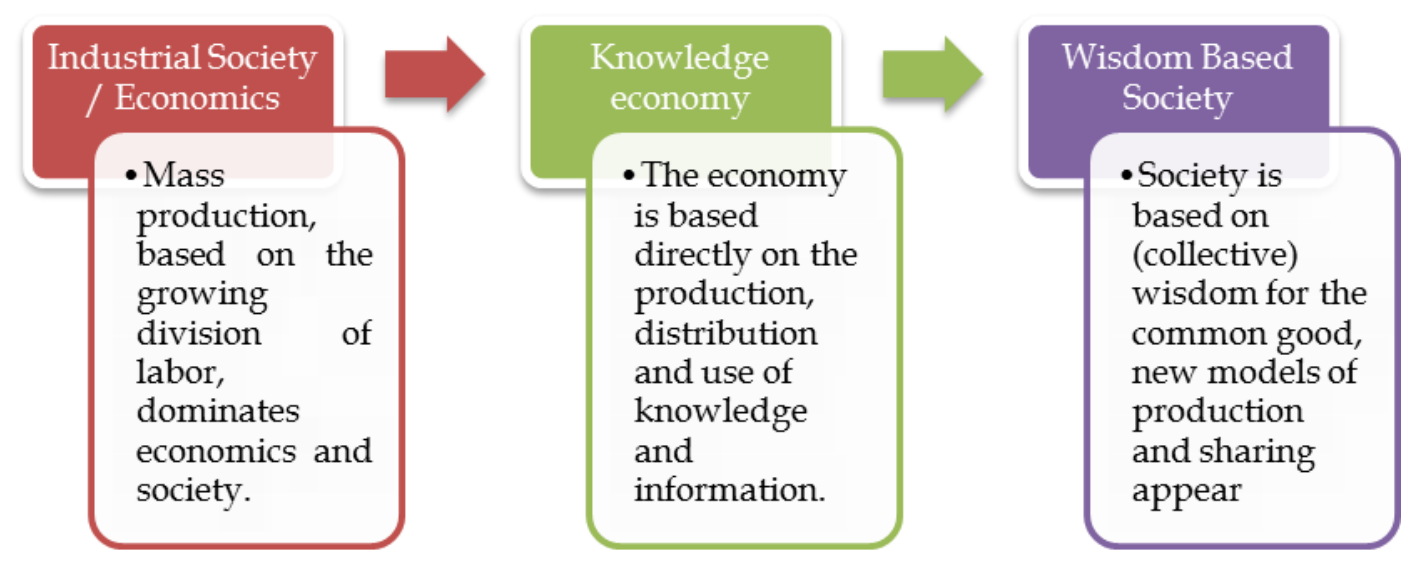

Figure 1: The emergence of a wisdom-based society

Transformation of educational systems on a global scale is facilitated by three main factors.

1. The growing complexity of socio-technical systems (such as transport, energy, telecom, mass production, etc.), socio-economic, political and cultural environments, which are increasingly acquiring the features of VUCA.

2. The growing inefficiency of the modern education system due to insufficient possibilities for its transformation, along with continued investment in industrial models of education and the reproduction of outdated "ways of cognition" (epistemology) that do not prepare society for answers to the challenges of the 21st century.

3. Active development of information and communication technologies, mathematics, cognitive sciences, biopharmaceuticals and other related sciences, 
providing incredible mobility, the ability to process "big data", automation of a number of cognitive processes in artificial intelligence systems, as well as new ways of personal and collective learning and development based on these tools.

This creates ideal conditions for the emergence of open personal (network) education based on relevant and advanced content, involving many new educational providers, cooperation between learners and teachers, creating motivating interactive educational environments and spaces. All this will allow educational systems to become more flexible, varied and personalized - and at the same time more and more global.

Numerous global challenges not only pose a threat to our existence - but also open up opportunities for updating ways of thinking, creativity, decisionmaking and activities. There is an unprecedented basis for cooperation, creativity and innovation on a global scale. Education becomes both a response to emerging challenges, and the main point of influence for the emergence of a complex society and the self-realization of every person on Earth. If "evolution is the way of learning the Universe, and learning is the way of man's evolution" (Laszlo, 2018), then the human community expects a focused development of the ability to learn and lead in such a way that together create a prosperous and desirable future on Earth and, possibly, beyond.

Global changes in attitude towards work and lifestyle mean a growing demand for new individual and collective competencies. In a complex society, universal knowledge and methods of action disappear, and much more important than specific competencies (that is, the ability to act effectively in a given context) are meta-competencies - such as creative abilities, the ability to negotiate and collaborate, empathy, etc. Similar "soft" skills are becoming increasingly important for getting a job, building a successful career, professional selfrealization, improving the quality of life and implementing an active citizenship.

Professional and social life is radically changing: more and more people are involved in creative activities in horizontal, globally distributed organizations and communities supported by information technology. Work in such organizations does not contradict the achievement of personal and more global social goals, and continuous development in them becomes a requirement and an integral part of life. These changes are reinforced by the accelerating transformation of global markets and supply chains, the massive disappearance of traditional areas of employment and the emergence of new areas of work caused by the flow of technological and social innovations, the spread of new global technological, financial and environmental standards. In these conditions, organizations, communities, regions and economies seek to strengthen their competitive advantages - and this leads to massive demand for "competencies of the future", allowing people to successfully operate in the context of the expected socio-economic and technological changes. A common understanding of future competencies includes (SES, 2012; PwC, 2013; OECD, 2019; Skidelsky, 2020):

1. various professional ("hard") competencies and knowledge associated with changes in technology and organization of work; 
2. "soft" professional competencies and universal knowledge that can be applied in all professions, social and personal situations (including those associated with the wave of technological transformation), such as (Regine,2020; Singh \& Sharma, 2020):

- competencies and knowledge that help to cope with the fundamental variability, uncertainty, complexity and ambiguity of the future - including competencies of cooperation, creativity, entrepreneurship, etc., as well as competencies related to strengthening personal "sustainability" (for example, acquisition healthy habits and the ability to cope with stress) and the ability to understand the future (understand and / or implement various scenarios of the future and develop appropriate strategies for individual and collective actions);

- competencies and knowledge that help to cope with the growing complexity of civilization - including systemic thinking, the ability to solve problems and find new opportunities (as well as artistic, poetic and other thinking), etc.

- knowledge and competencies that help to live in the world of information and communication technologies - including basic programming skills, information retrieval, processing and analysis skills (for example, "knowledge mapping", mind - mapping), information hygiene / media literacy, etc. One of the most important skills is the ability to manage your attention, the basic ability to direct and hold attention in the face of information overload (which can be trained through many contemplative practices);

- knowledge and competencies related to what "machines cannot do" including empathy / emotional or interpersonal intelligence, bodily - kinesthetic intelligence and naturalistic intelligence, as well as strengthening the ability to create and sincerely serve others;

- knowledge and skills related to focused multidisciplinarity, the desire to achieve mastery in various fields of work and life.

In addition, the ability to succeed in the expected future depends on the fundamental aspects of the human personality that determine how she lives and acts - what is often called "character" (OECD, 2019). Character traits are usually considered congenital or emerging at an early age. Nevertheless, modern approaches to psychotherapy and human development methods show that even fundamental character traits (eg. optimism) (Rashid \& Seligman, 2018) or "developmental orientation" (Diener \& Dweck, 1980) can be acquired and adjusted in any age. Therefore, such "life strategies" can be considered competencies of a special type, which we designate as "existential competencies". These competencies include the ability to set goals and achieve them (willpower), the ability to self-awareness / introspection (awareness), the ability to learn something / unlearn / relearn (self-development) and others.

Probably, the classification of "soft" skills is also worth clarifying, since many of them (for example, cooperation skills) are much more complex, based on more basic and universal competencies (for example, communication skills or emotional intelligence). 
Table 1: Life cycle of types of knowledge and skills

\begin{tabular}{|c|c|c|c|}
\hline \multirow{5}{*}{ 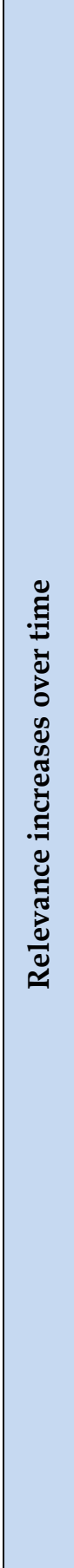 } & $\begin{array}{c}\text { TYPE OF KNOWLEDGE } \\
\text { AND SKILLS }\end{array}$ & $\begin{array}{c}\text { EXAMPLES OF } \\
\text { KNOWLEDGE AND } \\
\text { SKILLS }\end{array}$ & $\begin{array}{c}\text { APPROXIMATE } \\
\text { DURATION OF } \\
\text { ACTUALITY, } \\
\text { TIME FOR } \\
\text { THEIR } \\
\text { DEVELOPMENT }\end{array}$ \\
\hline & $\begin{array}{c}\text { CONTEXT (INCLUDING } \\
\text { NARROW } \\
\text { PROFESSIONAL) } \\
\text { KNOWLEDGE AND } \\
\text { SKILLS }\end{array}$ & $\begin{array}{l}\text { Highly specialized } \\
\text { knowledge } \\
\text { and } \\
\text { knowpetencies (for example, } \\
\text { surgical techniques for the } \\
\text { surgeon), special physical } \\
\text { skills (for example, cycling) } \\
\text { or special social skills (for } \\
\text { example, video blogging) }\end{array}$ & $\begin{array}{l}\text { From several } \\
\text { months to several } \\
\text { years }\end{array}$ \\
\hline & $\begin{array}{l}\text { CROSS-CONTEXT } \\
\text { (INCLUDING OVER- } \\
\text { PROFESSIONAL) } \\
\text { KNOWLEDGE AND } \\
\text { SKILLS }\end{array}$ & $\begin{array}{l}\text { Knowledge and } \\
\text { competencies that can be } \\
\text { applied in more areas of } \\
\text { socio-economic and } \\
\text { individual activity, for } \\
\text { example, reading, writing, } \\
\text { time management, } \\
\text { cooperation, etc. }\end{array}$ & \multirow[t]{2}{*}{$\begin{array}{l}\text { From a few years } \\
\text { to decades }\end{array}$} \\
\hline & $\begin{array}{l}\text { META-KNOWLEDGE } \\
\text { AND SKILLS }\end{array}$ & $\begin{array}{l}\text { Ways to operate objects in } \\
\text { consciousness or in physical } \\
\text { reality. First of all, various } \\
\text { methods of cognition and } \\
\text { creativity, including logical } \\
\text { and cognitive, emotional, } \\
\text { physical and other intellects }\end{array}$ & \\
\hline & $\begin{array}{c}\text { EXISTENTIAL } \\
\text { KNOWLEDGE AND } \\
\text { SKILLS }\end{array}$ & $\begin{array}{l}\text { The fundamental } \\
\text { competencies that determine } \\
\text { the essence of a person's } \\
\text { behavior in life, his } \\
\text { perception of situations and } \\
\text { his character, including } \\
\text { competencies that determine } \\
\text { willpower, health, emotional } \\
\text { self-regulation, self- } \\
\text { knowledge and introspection } \\
\text { abilities, self-development } \\
\text { skills, etc. }\end{array}$ & $\begin{array}{l}\text { From decades to a } \\
\text { lifetime }\end{array}$ \\
\hline
\end{tabular}

To take into account the diversity of competencies, we propose the use of the following four-level competency model, presented in Table 1, where four types of competencies are presented: competencies associated with a specific context; cross - contextual competencies; meta-competencies (primarily, types of thinking); existential competencies.

It takes different amounts of time to master the competencies of different levels. Context competencies can be mastered or adjusted in a short learning period, 
but they can also quickly become obsolete due to a constantly changing situation (for example, the competencies of working with word processing programs or a machine for mechanical processing, as they may become unnecessary due to changes in technology.). Cross-contextual competencies retain their relevance longer (over years or even decades), but they take more time to master. Metacompetencies, especially existential ones, remain relevant for the longest time. They usually develop early in a person's formation and rarely change during life. However, those who are capable of intentionally improving their "existential competencies" can also change many aspects of their lives.

The question arises, what part of these skills should be studied and at what level (secondary education, higher education). In the 2020 GRALE report (Global Report on Adult Learning and Education), rethinking the concept of literacy begins with the conclusion that "literacy" is usually perceived as the ability to read and write. In addition, the report increasingly mentions language skills, since most people live in a multilingual society or have a migrant background, using oral and written communication in different languages (Walters,2020).

This scheme determines that many future skills will be based on technical competencies, using ICTs and the Internet. The skills of the 21st century (Bourn, 2018) are the integration of skills in technological singularity. It is the formation of such skills that will be the main component of the curriculum in higher education institutions for adaptation in the business environment.

Thus, according to the report "The Future of Education" (Cedefop, 2010), Cedefop predicts an increase in demand in Europe for higher and secondary education. The report provides an analysis of how to change the demand in different professions in the future. The demand for highly qualified specialists is increasing: legislators, top managers, technical support professionals, and salespeople. The demand for clerks, artisans, workers in agriculture and fisheries is decreasing.Visualization of future learning outcomes is shown in Figure 2.

Today, few doubt that the future of any company directly depends on its ability to manage knowledge. The development of procedures for the detection, transmission, replenishment and exchange of knowledge becomes one of the main areas of activity of leading companies. A good tool for this is knowledge management, which is defined as the interaction between People, Places, and Things in a meaningful context. In the conditions of an innovative economy, in the process of knowledge management, one must also take into account a number of factors, the priority of which is: human, technological, individual, organizational, global, factor of time.

The "competencies of the future" (or "competences of the 21st century") are aimed at satisfying the need to change economic and social systems. By mastering the "competencies of the future", we can become more complex people and communities that are able to live in a new complex society. 


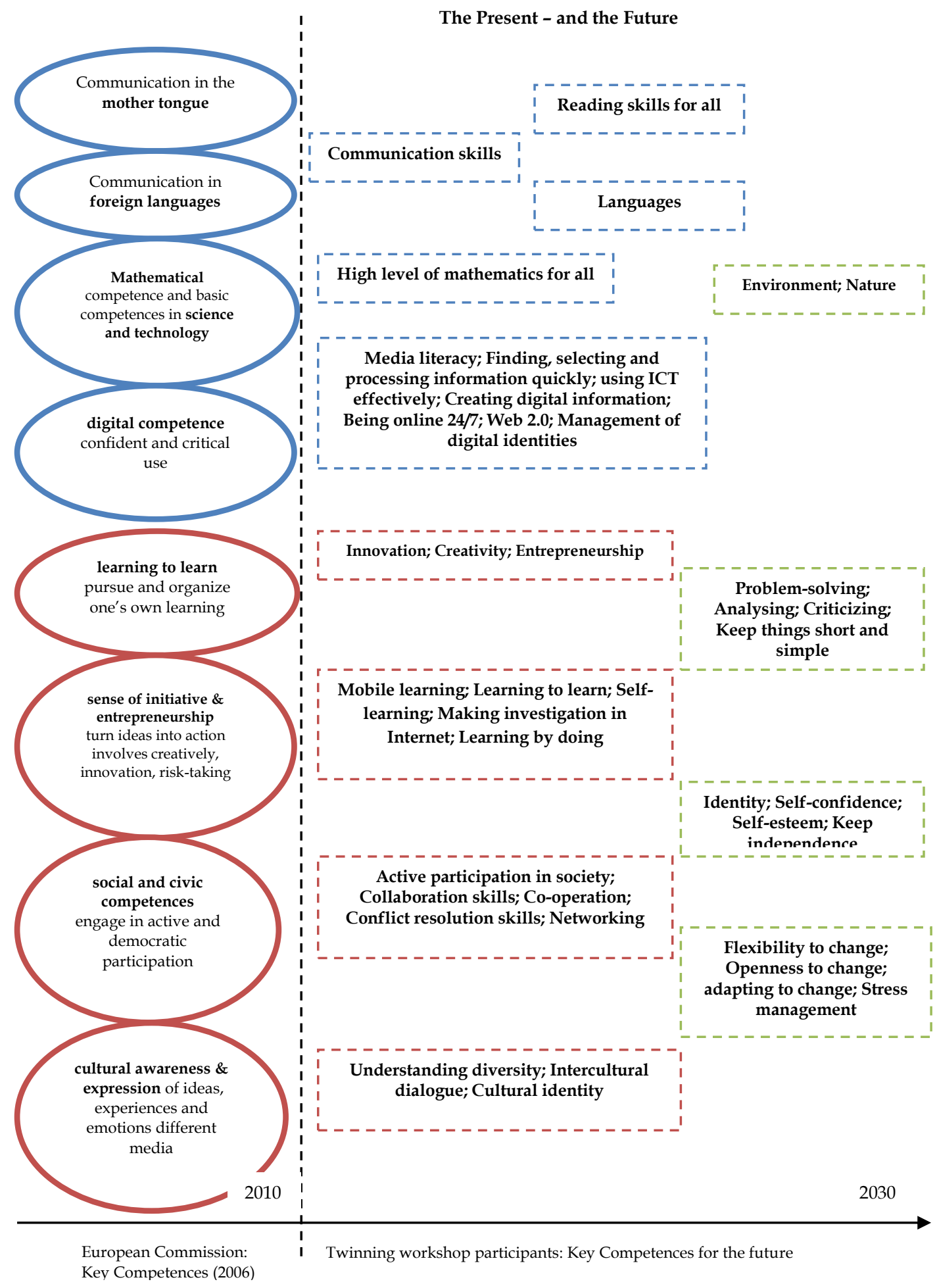

Figure 2: Visualization of future learning outcomes

Moreover, the development of society and the economy in the direction of greater complexity will occur faster and will be all the more sustainable as the larger percentage of the population in large numbers can master these competencies of the future. However, today there is a gap between traditional 
education systems and the learning process that is required to master the "skills of the future."

\section{Results}

Accelerating social and cultural change places additional demands on the continuous updating of skills and knowledge. As a result, the processes of the "new" education should have greater flexibility and greater diversity compared with existing educational systems. In contrast to the "hard" educational practices of institutions of the industrial era, educational ecosystems allow the most comprehensive way to integrate the diversity of educational opportunities available in a particular territory. Educational ecosystems can include both real and virtual spaces, provide opportunities for individual and collective development in a wide range of human activities. They can also take into account the needs of learners that appear and change throughout their lives, including the processes of transition through life stages, social roles and skill levels - the processes of "initiation" education, which should again revive in our culture.

Princeton University and University College London conducted a study aimed at determining how the use of artificial intelligence could affect the education of students (Driscole,2018). Princeton University commissioned a research company McKinsey \& Company research, the essence of which was that during the course of the semester, an MRI scan of students is carried out to study artificial intelligence and understand how the learning process affects changes in the brain. Namely, it analyzes how many times a student looks at lectures, how quickly he understands the essence, which parts of the learning he is given the hardest. The research results help to create a more personalized learning product that promotes learning even faster.

China is actively using robots in classrooms as teachers and learners assistants. The State Council of China announced the use of artificial intelligence in primary and secondary education. In 2018, the first textbook on artificial intelligence for high schools was created in China. Japan also began using robots to teach English in their private schools (Andriushchenko, Kovtun et al., 2019).

According to the constant technological singularity, algorithms of machine learning are developing rapidly. And the software, approaches and models on which they learn are enormous. That is why, in the era of digitalisation, the competence to use information and communication technologies are the necessary and crucial condition for survival and the search for good work. The gap between those who can freely use ICTs and those who cannot even afford access to ICT will eventually scale (Hubanova et al., 2020).

In 2009, the Joint Research Center of the European Commission, the Institute for Prospective Technological Studies in Seville, began a large-scale research to study "Future Education". The purpose of this research, which is shown in Figure 3, is strategy formulation in the field of the education system that would adequately prepare learners for life in the future society. As well as what competences they will need for self-realization and development of society in 
the period 2020-2030. This research is based on the "Learning Spaces in the Future" (Badia, 2006; Redecker \& Punie,2013; Anastasiades, 2016).

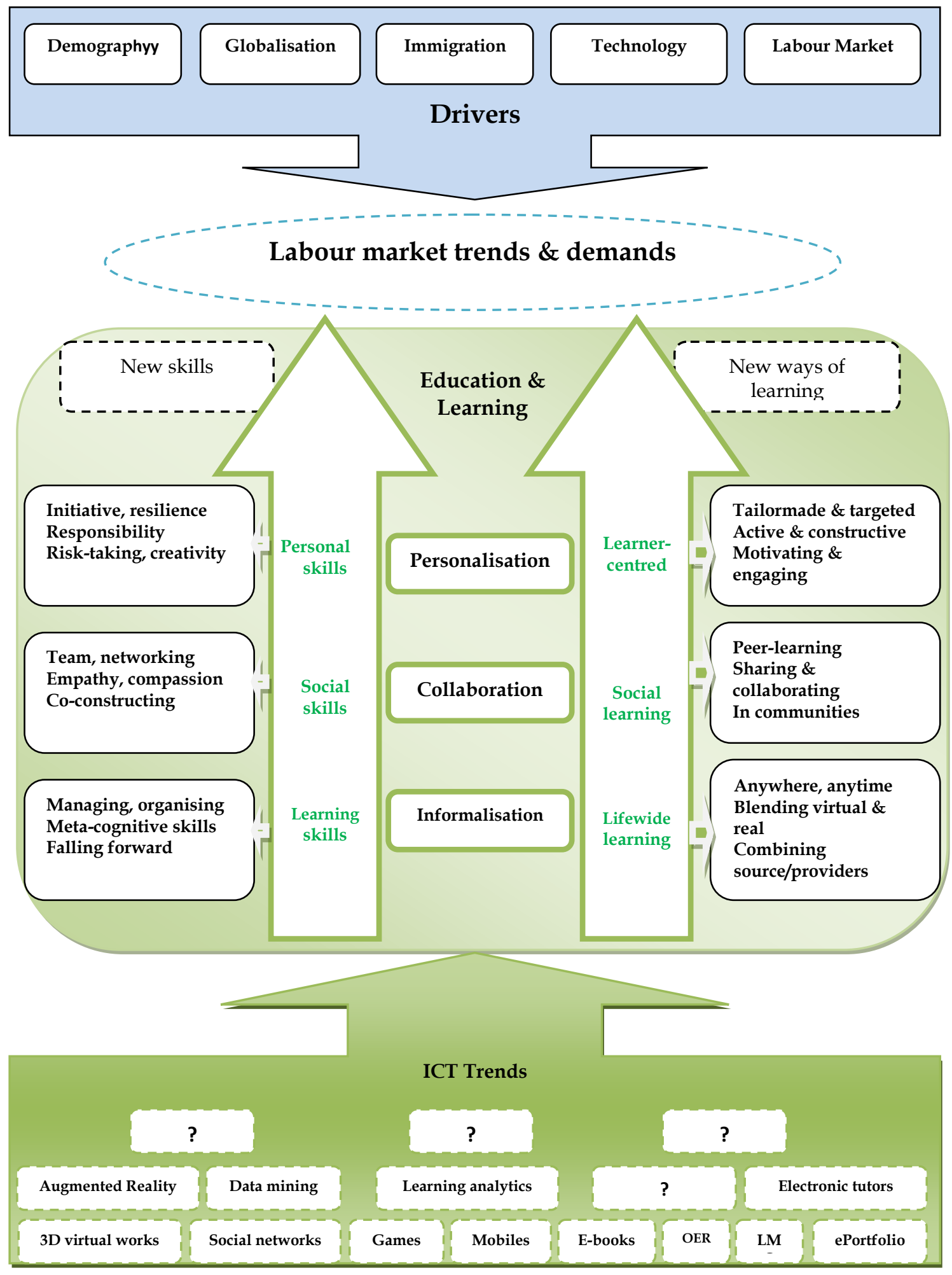

Figure 3: Conceptual map of the future of learning 
To ensure the health of the educational ecosystem, it is necessary to create tools and processes that support personal and collective learning and development throughout life, including:

- processes and tools that help define the goals (individual or collective) of learners, analyze their motivation to learn and preferred learning formats (for example, learning in a competitive environment, in collaboration or through individual research; reward based on internal or external rewards, etc.);

- educational processes that are integrated into the (individual or collective) educational trajectory and develop various aspects of personal and collective existence (cognitive, social, emotional, physical) through holistic educational experiences, including play and co-creation;

- processes and tools that measure learning outcomes (such as new acquired competencies, artifacts created as a result of creative learning, reputation gained through participation in educational experience, etc.), as well as indicators of the quality of the educational process (level of interaction, level of joy, etc.);

- educational technologies that support personal and collective education processes, including virtual personal assistants and various educational resources;

- educational spaces and technologies that help connect personal and collective educational trajectories, aligning individual educational needs with evolving community needs.

These processes can be integrated into "ecosystem" systems of educational process management (in which personal and collective learning paths can be combined, and which connect learners with many learning spaces and educational opportunities). In the logic of such a model, the educational institutions that we are familiar with (schools and universities) may exist as some of the sites offering educational opportunities - or, they may become centers of educational ecosystems, where educational processes are supported by a number of educational technologies, including:

1. Solutions that enhance the individual educational process (due to applications using "big data" and artificial intelligence), including: virtual tutors, personal virtual assistants ,; personalized interactive learning materials and applications; personal wearable devices for monitoring the psychophysical state, etc.

2. Solutions that enhance collective educational processes, including: collective virtual assistants (facilitators, moderators) that support the productive work of the group; collective self-regulation tools, etc.

3. Solutions combining individual and collective educational processes, including:

- knowledge repositories (online libraries of books, articles, simulations, online encyclopedias), as well as educational online platforms (with curated content);

- educational spaces for cross-learning (peer - to - peer) training and mentoring support, including social networks and online gaming universes (including virtual and augmented reality); 
- "markets of opportunities", connecting individual learners with educational opportunities existing in organizations and communities, including requests for participation in a project / task / game (such "markets" can be imagined as online platforms for job search with significantly wider functionality.

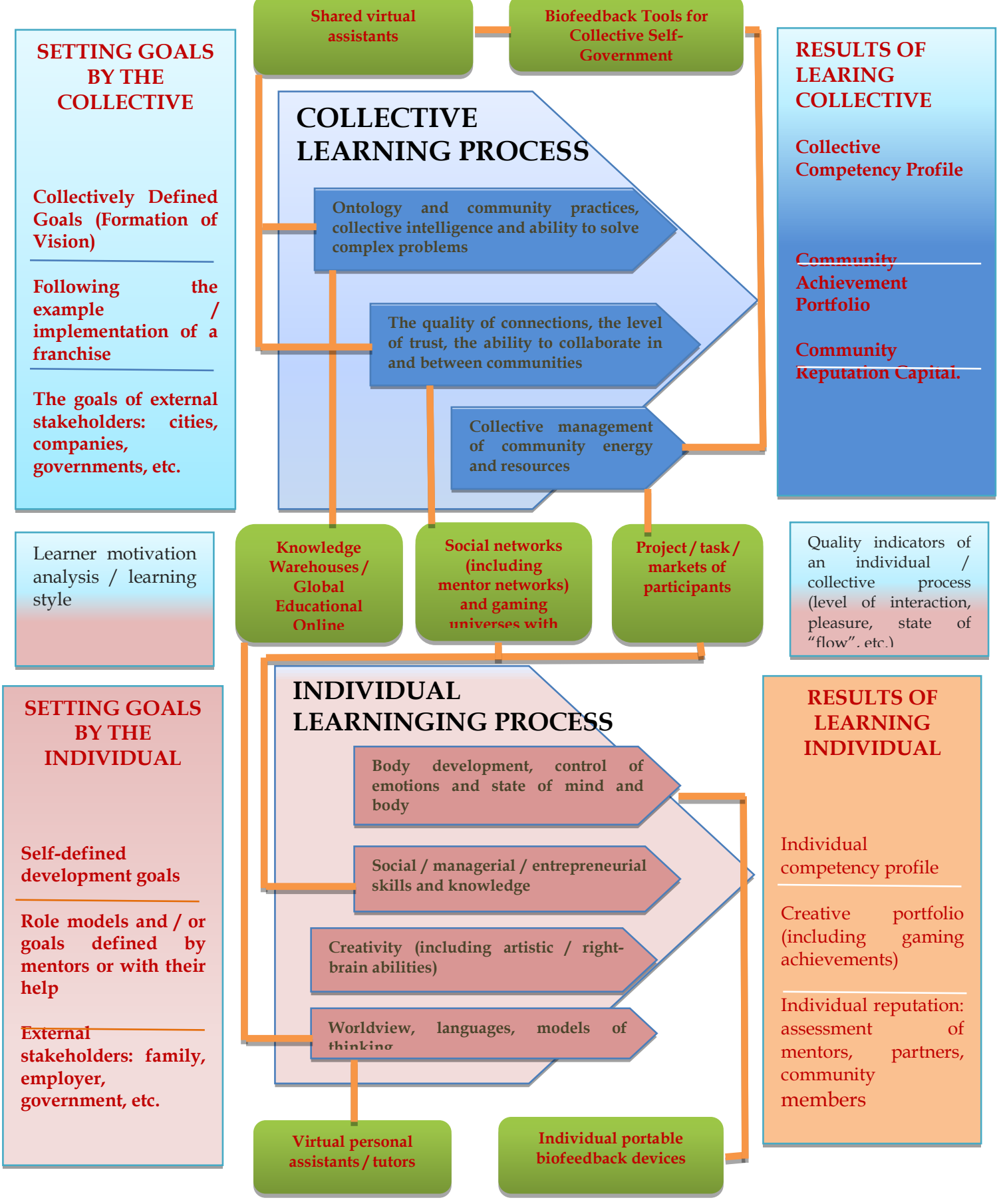

Figure 4: Visualization of the learning process of the future

Since learners can participate in one or several educational communities, and any community will involve many simultaneously studying people at different stages of development, it is necessary to create synergies between educational 
experiences through their dynamic interaction. In the course of collective learning, learners are offered certain roles and specific tasks, and their individual educational experiences "collect" collective educational experience. At the same time, collective learning possesses the properties of synergetic phenomena and cannot be reduced to the "sum of its parts" - in the process of such learning, collective competencies arise that are unique to each educational community. Visualization of the learning process of the future is presented in Figure 4.

Thus, education becomes an integral part of human life: part of work, creativity, family, play, love and any other human affairs. In VUCA - the world, responsibility for one's own life and development cannot be shifted solely to external forces (school, teachers, parents), and development cannot be ensured through a system of rewards and punishments (Liezina et al. 2020). At present, schools and universities often perform a disciplinary function and force people to study and engage in self-development. But as the world becomes more complex and less predictable, the only way to strengthen the sustainability of society in the long run is to assign to everyone its responsibility for their own education. Moreover, all the main educational innovations that have been discussed over the past 20 years - personalization and individual trajectories, online platforms and learners studying from each other, etc., require the transformation of a critical mass of society from passive consumers of knowledge into active "self-guided" learner. The architecture of the educational ecosystem of the future is shown in Figure 5.

PERSONALIZED LEARNING BASED ON DIGITAL TECHNOLOGIES

Educational technologies that help create personalized trajectories in education, career, wealth

\section{SELF-GUIDED LEARNERS}

Natural education throughout life always and everywhere

Learning Skills of the Future

\section{COLLECTIVE LEARNING FACE TO} FACE

mutual supportive and orienting communities of practice

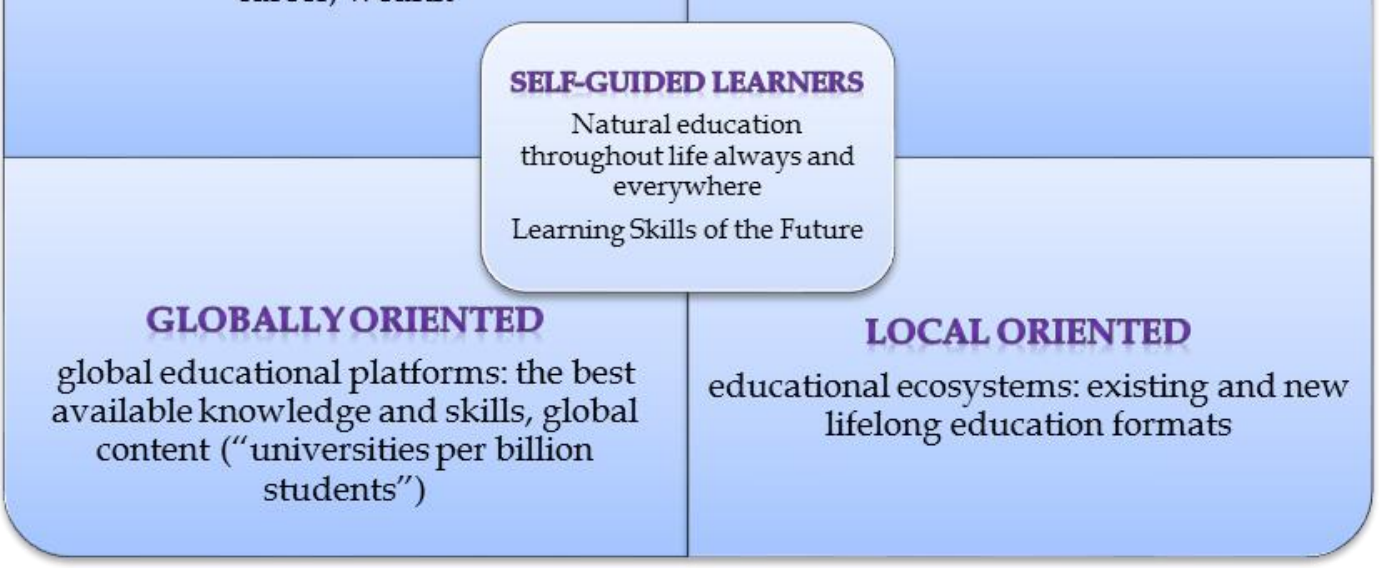

Figure 5: Model of the educational ecosystem of the future

From the leaner's perspective, this multidimensional space can be described through at least two semantic axes:

- Local / global formats: some educational opportunities are built around local content and direct physical contact (for example, group projects at school or 
learning in an urban environment), while others are based on global content and remote interaction (for example, learning on global online - platforms);

- Human-to-human / human-to-technology contact: some educational processes take place in the form of mentoring or peer education, while others are created by technology, online resources, video games and wearable devices.

In addition to schools and universities, which will remain a significant part of ecosystems, but will gradually turn into "pillars" of educational network spaces - as ecosystems develop, at least three other spaces will become increasingly important:

- global educational online platforms will become the ultimate providers of global knowledge and educational content;

- urban education formats will continue to evolve in response to the growing needs of "self- guided" learners of all ages;

- spaces of continuing education will be built around high-tech personalized educational experiences, as well as collective experiences of human interaction and co-creation.

A "self-guided" learner is able to set the goals of his learning, determine the pace and other parameters of the learning process, use and create the necessary educational resources, and immerse himself in various educational experiences (including experiences whose results cannot always be predicted) that ensure holistic development throughout all life. Moreover, it is "self-guided" learners that create a request for new personalized educational formats using new technologies, including online courses, educational applications, training through practice, etc. So, the learning process should be diverse (limited in time, personalized, comprehensive). Learners should be at the center of this process, and this is important in order to acquire the competencies of the 21st century.

\section{Conclusion}

The increase in the percentage of self-guided learners to the level of "critical mass" (according to recent studies (Global Education Futures. 2020), about 10\%) is the main prerequisite for the start of a "revolution in education ". Therefore, we believe that in the next decade, educational innovations should be aimed primarily at developing formats that ensure the transition to a new state: first of all, at pedagogy and andragogy, which can significantly increase the level of independence and self-government. Educational institutions interested in joining this process and wishing to become part of the "new" educational environment need to strengthen the component related to the formation of relevant competencies, including the formation of motivation for learning and development, setting personal goals, choosing educational technologies and practices, selecting / creating leading content. If we move to mass self-guided education throughout life, it is obvious that it is necessary to move away from the usual concept of "continuing education" as professional development in adulthood (and often in the workplace) - on the contrary, it is necessary to develop and maintain various aspects of the human personality, and not just those associated with a dominant social role. Genuine continuing education will 
not only mean preparing for overcoming the challenges of certain periods of life (for example, socialization or the beginning of professional activity), but also will deal with thresholds and transitions between these periods - that is, accompany the change of a person's social roles. In a world of high uncertainty, education cannot have a predetermined ultimate goal - it is an individual and joint journey in which we not only learn to learn but help each other move along the development path.

\section{References}

Anastasiades, P. (2016). ICT and Collaborative Creativity in Modern School Towards Knowledge Society. Research on e-Learning and ICT in Education, 17-29. doi:10.1007/978-3-319-34127-9_2

Andriushchenko K., Kovtun V., Shergina L., Rozhko O., \& Yefimenko L. (2020). Agrobased Clusters: A tool for effective management of regional development in the ERA of globalisation. TEM Journal, 2020, 9(1), 198-204. doi: 10.18421/TEM91-28

Andriushchenko, K., Buriachenko, A., Rozhko, O., Lavruk, O., Skok, P., Hlushchenko, Y., Muzychka, Y., Slavina, N., Buchynska, O., \& Kondarevych, V. (2020). Peculiarities of sustainable development of enterprises in the context of digital transformation. Entrepreneurship and sustainability issues, 7(3), 2255-2270. doi: 10.9770/jesi.2020.7.3(53)

Armstrong, S. (2017). Introduction to the Technological Singularity. The Technological Singularity, 1-8. doi:10.1007/978-3-662-54033-6_1

Badia, T. (2006). Monograph "Teaching and learning with ICT in higher education." RUSC. Universities and Knowledge Society Journal, 3(2). doi:10.7238/rusc.v3i2.282

Baltes, P. B., \& Staudinger, U. M. (2000). Wisdom: A metaheuristic (pragmatic) to orchestrate mind and virtue toward excellence. American Psychologist, 55(1), 122136. doi:10.1037/0003-066x.55.1.122

Bilan, Y., Nitsenko, V., Ushkarenko, I., Chmut, A., \& Sharapa, O. (2017). Outsourcing in international economic relations. Montenegrin Journal of Economics, 13(3), 175-185. doi:10.14254/1800-5845/2017.13-3.14

Bourn, D. (2018). From 21st Century Skills to Global Skills. Understanding Global Skills for 21st Century Professions, 63-85. doi:10.1007/978-3-319-97655-6_4

Calum, C. (2018). The Technological Singularity. Artificial Intelligence and the Two Singularities, 175-180. doi:10.1201/9781351254465-12

Cedefop. (2010). Skills supply and demand in Europe. Medium-term forecast up to 2020. European Centre for the Development of Vocational Training launches online survey. Industrial and Commercial Training, 33(7). doi:10.1108/ict.2001.03733gab.003

Chapin, F. S, Matson, P, \& Mooney, H. (2002). Principles of Terrestrial Ecosystem Ecology. New York, USA: Springer.

Coser, L. A., \& Mumford, L. (1972). The Pentagon of Power. Volume II of the Myth of the Machine. Contemporary Sociology, 1(1), 38. doi:10.2307/2063904

Diener, C. I., \& Dweck, C. S. (1980). An analysis of learned helplessness: II. The processing of success. Journal of Personality and Social Psychology, 39(5), 940-952. doi:10.1037/0022-3514.39.5.940

Driscole, R. E. (2018). Employment opportunities and skills necessary for entry-level employment in the timber industry. doi:10.33915/etd.1961

Eden, A. H., Steinhart, E., Pearce, D., \& Moor, J. H. (2012). Singularity Hypotheses: An Overview. Singularity Hypotheses, 1-12. doi:10.1007/978-3-642-32560-1_1 
Global Education Futures. (2020). Educational Ecosystems for Societal Transformation. Global Education Futures. Retrieved from http://www.globaledufutures.org/images/people/GEF_april26-min.pdf

Good, I. J. (1990). Speculations concerning the future of statistics. Journal of Statistical Planning and Inference, 25(3), 441-466. doi:10.1016/0378-3758(90)90088-c

Hannon, V. (2017). Thrive: Schools Reinvented for Real Challenges We Face. London, England: Innovation Unit Press.

Hansson, A. (1990). Envisioning a sustainable society: Learning our way out. Futures, 22(9), 980-981. doi:10.1016/0016-3287(90)90069-t

Hays Global Skills Index. (2018). Investing in the skills of tomorrow avoiding a spiralling skills crisis. Hays plc. Retrieved from https://www.haysindex.com/core/uploads/2018/09/Hays-Global-Skills-Index-2018-Report.pdf

Heylighen, F. (2015). Accelerating Socio-Technological Evolution: from ephemeralization and stigmergy to the global brain. Retrieved from http:// pcp.vub.ac.be/Papers/AcceleratingEvolution.pdf

Hubanova, T., Shchokin, R., Hubanov, O., Slobodianiuk, P., \& Drobotov, S. (2020). Special criminological principles of crime prevention in the field of intellectual property. International journal of management, Volume 11, Issue 7, 938-952. doi:10.34218/IJM.11.7.2020.082

Jacobs, G. (2014). New Paradigm: The Necessity and the Opportunity. Cadmus, 2(2), 9-23

Johannessen, J.-A., \& Sætersdal, H. (2020). Singularity and education. Automation, Innovation and Work, 130-148. doi:10.4324/9781003032854-9

Knowledge Works. (2012). Recombinant Education: Regenerating the Learning Ecosystem. Knowledge Works Forecast. Retrieved from http://knowledgeworks.org/sites/default/files/u1/Forecast3_0.pdf

Kovtun, V., Andriushchenko, K., Horbova, N., Lavruk, O., \& Muzychka, Y. (2020) Features of the Management Process ofAmbidextrous Companies. TEM Journal, 9(1), 221-226. doi:10.18421/TEM91-31

Kurzweil, R. (1999). The Age of Spiritual Machines: When Computers Exceed Human Intelligence. New York, USA: Penguin.

Kurzweil, R. (2005). The Singularity Is Near. New York, USA: Viking Adult.

Kurzweil, R. (2008). The singularity: The last word - [forum]. IEEE Spectrum, 45(10). doi:10.1109/mspec.2008.4635038

Kurzweil, R. (2016). Superintelligence and Singularity. Science Fiction and Philosophy, 146170. doi:10.1002/9781118922590.ch15

Laszlo, A. (2018). Education for the future: The emerging paradigm of thrivable education. World Futures, 75(3), 174-183. doi:10.1080/02604027.2018.1463760

Liezina A., Andriushchenko K., Rozhko O., Datsii O., Mishchenko L., \& Cherniaieva O. (2020). Resource planning for risk diversification in the formation of a digital twin enterprise. Accounting, 6, 1337-1344. doi.org: 10.5267/j.ac.2020.8.016

Mead, W. R., \& Kurzweil, R. (2006). The Singularity Is near: When Humans Transcend Biology. Foreign Affairs, 85(3), 160. doi:10.2307/20031996

Mole, C. (2011). Nineteen Fifty-Eight: Information Technology and the Reconceptualisation of Creativity. The Cambridge Quarterly, 40(4), 301-327. doi:10.1093/camqtly/bfr030

Neumann, J. (1993). First draft of a report on the EDVAC. IEEE Annals of the History of Computing, 15(4), 27-75. doi:10.1109/85.238389

Nitsenko, V., Mardani, A., Streimikis, J., Ishchenko, M., Chaikovsky, M., StoyanovaKoval, S., \& Arutiunian, R. (2019). Automatic Information System of Risk Assessment for Agricultural Enterprises of Ukraine. Montenegrin Journal of Economics, 15(2), 139-152. doi:10.14254/1800-5845/2019.15-2.11 
OECD. (2019). OECD Employment Outlook 2019. OECD Employment Outlook. doi:10.1787/9ee00155-en

Panov, A. (2020). Singularity of Evolution and Post-singular Development in the Big History Perspective. The 21st Century Singularity and Global Futures, 439-465. doi:10.1007/978-3-030-33730-8_20

Pearce, A., \& McCoy, A. (2007). Creating an Educational Ecosystem for Construction: A Model for Research, Teaching, and Outreach Integration and Synergy. Virginia, USA: Myers-Lawson School of Construction, Department of Building Construction, VirginiaTech.

Psacharopoulos, G., \& Patrinos, H. A. (2018). Returns to Investment in Education: A Decennial Review of the Global Literature. Policy Research Working Papers. doi:10.1596/1813-9450-8402

PwC. (2013). World in 2050. The BRICs and Beyond: Prospects, Challenges and Opportunities. PricewaterhouseCoopers LLP. London, England. Retrieved from http://www.pwc.com/en_GX/gx/world-2050/assets/pwc-world-in-2050-reportjanuary-2013.pdf.

Rashid, T., \& Seligman, M. (2018). Session Nine: Hope and Optimism. Positive Psychotherapy, 68-71. doi:10.1093/med-psych/9780190920241.003.0010

Redecker, C., \& Punie, Y. (2013). The Future of Learning 2025: Developing a vision for change. Future Learning, 2(1), 3-17. doi:10.7564/13-fule12

Regine, B. (2020). Inclusive Leadership and Soft Skills. The Routledge Companion to Inclusive Leadership, 264-272. doi:10.4324/9780429294396-25

SES. (2012). Skills and Employment Survey 2012. Technical Report prepared for Cardiff University. The Skills and Employment Survey. Retrieved from http://www.cardiff.ac.uk/socsi/ses2012/index.html

Singh, D., \& Sharma, D. (2020). Employability Skills to Thrive during Fourth Industrial Revolution:Upskilling Secondary School Learners. Jaipuria International Journal of Management Research, 6(1), 3. doi:10.22552/jijmr/2020/v6/i1/195903

Skidelsky, R. (2020). The Future of Work. Work in the Future, 9-21. doi:10.1007/978-3-03021134-9_2

Solez, K., Bernier, A., Crichton, J., Graves, H., Kuttikat, P., Lockwood, R., ... Zakus, D. (2013). Bridging the Gap between the Technological Singularity and Mainstream Medicine: Highlighting a Course on Technology and the Future of Medicine. Global Journal of Health Science, 5(6). doi:10.5539/gihs.v5n6p112

Tapscott, D. (1997). Strategy in the new economy. Strategy \& Leadership, 25(6), 8-14. doi:10.1108/eb054601

Toffler, A. (1970). Future Shock. New York, USA: Random House.

Tsirel, S. (2020). Future Technological Achievements as a Challenge for Post-singularity Human Society. The 21st Century Singularity and Global Futures, 419-437. doi:10.1007/978-3-030-33730-8_19

Ulam, S. (1958). John von Neumann 1903-1957. Bulletin of the American Mathematical Society, 64(3), 1-50. doi:10.1090/s0002-9904-1958-10189-5

UNESCO. (2020). Education Building-Blocks. Retrieved from http://www.unesco.org/new/ en / education / themes / educationbuildingblocks / literacy / resources / statistics

Vinge, V. (2008). Signs of the singularity. IEEE Spectrum, 45(6), 76-82. doi:10.1109/mspec.2008.4531467

Walters, S. (2020). 4th Global report on adult learning and education - Leave no one behind: Participation, equity and inclusion. Studies in the Education of Adults, 1-2. doi:10.1080/02660830.2020.1770486 